\title{
Licófitas e monilófitas (Pteridophyta) da Floresta Nacional de Caxiuanã, estado do Pará, Brasil: chave para as famílias e as espécies de Aspleniaceae e Blechnaceae \\ Lycophytes and Monilophytes (Pteridophytes) of the Floresta Nacional de Caxiuanã, Pará State, Brazil: key to the families, and to species of Aspleniaceae and Blechnaceae
}

\author{
Marcio Roberto Pietrobom da Silval \\ Sebastião Maciel do Rosário"
}

\begin{abstract}
Resumo: Estão em desenvolvimento estudos florísticos, taxonômicos e ecológicos sobre as monilófitas ocorrentes nos vários ecossistemas paraenses. Considerando a grande carência de trabalhos científicos sobre a flora de pteridófitas da Amazônia, este trabalho foi desenvolvido como uma contribuição ao conhecimento de duas famílias ocorrentes na área selecionada para estudo, localizada nos municípios de Melgaço e Portel. A Floresta Nacional (FLONA) está posicionada geograficamente a 1037'S / 51019'W e 1054'S / 51058'W e limites sul de 2015'S / 51015'W e 2015'S / 51056'W, na microrregião dos Furos, nas proximidades da baía de Caxiuanã, entre os rios Xingu e Tocantins, com cerca de 200.000 ha. A FLONA é composta por florestas não inundáveis (floresta de terra firme, manchas de vegetação savanóide e capoeira) e florestas inundáveis (várzea e igapó), com predomínio da floresta de terra firme, além de abundante vegetação aquática. Para a identificação taxonômica dos espécimes coletados, foram utilizadas técnicas usuais e literaturas especializadas. Exsicatas representativas foram depositadas no Herbário "João Murça Pires" (MG), do Museu Paraense Emílio Goeldi, com duplicatas doadas para vários herbários do país. O estudo apresenta uma chave para identificação das famílias de Lycophyta e Monilophyta (Pteridophyta) ocorrentes na área e o tratamento taxonômico das famílias Aspleniaceae e Blechnaceae ocorrentes na FLONA de Caxiuanã. São apresentadas descrições das espécies e dos gêneros, ilustrações, chave para as espécies e gêneros, bem como comentários sobre todos os táxons. Na área de estudos, a família Aspleniaceae está representada por Asplenium angustum Sw., A. juglandifolium Lam. e A. serratum L., e a família Blechnaceae por Blechnum serrulatum Rich. e Salpichlaena hookeriana (Kuntze) Alston.
\end{abstract}

Palavras-chave: Taxonomia. Aspleniaceae. Blechnaceae. Pteridófitas. Floresta Amazônica.

Abstract: This study of the Aspleniaceae and Blechnaceae of the Caxiuanã National Forest (FLONA), is part of a series on the floristic, taxonomic and ecological studies of the Lycophyte and Monilophyte flora of the ecosystems of the Brazilian state of Pará. The FLONA is situated in the municipalities of Melgaço and Portel (1037'S / 51019' W and 1054'S / 51058' W and limits south of 2015'S / 51015'W and 2015'S / 51056'W) in the micro-region of Furos, in the bay of Caxiuanã, between the Xingu a Tocantins rivers, and occupies about $200.000 \mathrm{ha}$. The FLONA includes several vegetation types, including non-flooded (terra firme forest with islands of savanna-like and secondary forest) and flooded forest (várzea and igapó), well as abundant aquatic vegetation, the terra firme forest being the predominant type. Taxonomic identification was made following the usual methods and using the specialist literature. Representative specimens were deposited in the "João Murça Pires" (MG) herbarium of the Museu Paraense Emílio Goeldi and duplicates sent to other Brazilian herbaria. A key to the families of Lycophyta and Monilophyta (Pteridophyta) which occur in the area and a taxonomic treatment of the Aspleniaceae and Blechnaceae which occur in the FLONA are presented, with descriptions of the species and genera, illustrations, key to species and genera together with commentaries about the taxa. In the study area the family Aspleniaceae is represented by Asplenium angustum Sw., A. juglandifolium Lam. and A. serratum L. and the family Blechnaceae by Blechnum serrulatum Rich. and Salpichlaena hookeriana (Kuntze) Alston.

Keywords: Taxonomic. Aspleniaceae. Blechnaceae. Pteridophytes. Amazonian Forest.

\footnotetext{
Museu Paraense Emílio Goeldi. Coordenação de Botânica. Belém, Pará, Brasil (pietrobomsilva@yahoo.com).

"Universidade Federal Rural da Amazônia. Belém, Pará, Brasil (macielbio@yahoo.com.br).
}

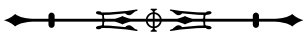




\section{INTRODUÇÃO}

Segundo Tryon \& Conant (1975), a diversidade das pteridófitas na Amazônia brasileira (licófitas e monilófitas) é considerada relativamente pobre e de baixo endemismo. Este fato representa um contraste acentuado em relação ao elevado endemismo de muitos gêneros de plantas superiores. Atualmente, estima-se aproximadamente 550 espécies para a região Norte (Prado, 2003). Para o estado do Pará, é referido, até o presente, aproximadamente 313 espécies, entre licófitas e monilófitas.

Os estudos sobre as licófitas e monilófitas no Pará foram iniciados por J. Huber, no final do século XIX, com os trabalhos desenvolvidos na Ilha do Marajó (Huber, 1898), onde foram registradas três espécies; na região dos "furos" de Breves (Huber, 1902), onde foram registradas 47 espécies, e nas proximidades de Bragança (Huber, 1906), em vegetação de igarapé, com o registro de Alsophila ferox Presl [= Cyathea microdonta (Desv.) Domin]. Outro trabalho pioneiro foi o de Sampaio (1930), que publicou a primeira coletânea de eufilicíneas da Amazônia, apresentando uma lista das espécies coletadas no rio Cuminá (afluente do rio Trombetas - Pará). Destacam-se também trabalhos mais recentes feitos na região metropolitana de Belém, como o de Rodrigues et al. (2004), que referiram 38 espécies na área de Pesquisa Ecológica do Guamá, o de Costa et al. (2006), que citam Trichomanes pinnatinervium Jenman como sendo primeiro registro para o Brasil, e J. M. Costa, que, em 2007, em sua dissertação de Mestrado, referiu 70 espécies de licófitas e monilófitas para a ilha de Mosqueiro.

Com relação à situação das famílias aqui estudadas, Aspleniaceae é a que possui mais trabalhos de cunho florístico, entretanto tem sido pouco estudada taxonomicamente. $\bigcirc$ trabalho mais amplo sobre a família para o Brasil foi desenvolvido por Sylvestre \& Windisch (2002), que tratam das novas combinações do gênero Antigramma C. Presl e da sinopse das espécies.

Estudos mais regionais referentes às espécies de Aspleniaceae no Brasil foram realizados por Pietrobom \& Barros (2001) para a Mata do Estado (Pernambuco), Sylvestre
\& Ramos (2005) para a Flora do Distrito Federal, e Prado (2005a) para a Flora da Reserva Ducke (Amazonas).

Em relação à família Blechnaceae, a escassez de estudos no Brasil é mais acentuada. No que se refere a esta família, tem-se Prado (2004), com os Criptógamos do Parque Estadual das Fontes do Ipiranga (São Paulo), e Prado (2005b), na Flora da Reserva Ducke (Amazonas).

A maioria dos trabalhos desenvolvidos na Floresta Nacional (FLONA) de Caxiuanã é espećfica para a Estação Científica Ferreira Penna (ECFPn), que se localiza dentro da FLONA. Na ECPFn, existem estudos a respeito de espermatófitas (Almeida et al., 1993, 1997; Lisboa et al., 1997), briófitas (Lisboa \& Nazaré, 1997; Luizi-Ponzo et al., 1997) e fungos (Sotão et al., 1997), dentre outros publicados em Lisboa (1997a). Sendo assim, o presente estudo é pioneiro sobre as monilófitas na FLONA de Caxiuanã, confirmando a necessidade de coletas e estudos para o grupo no estado do Pará, bem como na região Norte do país.

Desta forma, este estudo tem por objetivos apresentar uma chave analítica de identificação das famílias de Lycophyta e Monilophyta ocorrentes na FLONA de Caxiuanã, bem como informações taxonômicas sobre as espécies de Aspleniaceae e Blechnaceae, visando a facilitar a identificação dos táxons em futuros estudos, além de contribuir com o conhecimento da Flora do Pará e do Brasil.

\section{MATERIAL E MÉTODOS}

A região de Caxiuanã está situada na porção inferior do rio Anapu, entre os rios Tocantins e Xingu, Amazônia Oriental, nos municípios de Melgaço e Portel, estado do Pará, onde se situa a FLONA de Caxiuanã, com limites norte de 1037'S / 51019'W e 1054'S / 510 58'W e limites sul de 2015'S / 51015'W e 2015'S / 51056'W (Montag et al., 2008), pertencendo à microrregião dos Furos (IBGE, 1981). Abrange uma área de aproximadamente 200.000 ha (Brasil, 1961; Lisboa, 1997b).

A vegetação é caracterizada por floresta densa de terra firme, florestas de inundação (várzea e igapó), vegetação savanóide (campo hidromórfico), vegetação 
secundária (capoeira) e vegetação residual em sítios de pomares (Lisboa et al., 1997).

O tipo climático é Am - clima tropical úmido, classificação de Köppen, com excesso de precipitação pluviométrica durante alguns meses (outubro e novembro, com pluviosidade inferior a $60 \mathrm{~mm}$ ). A temperatura média anual é de cerca de $26^{\circ} \mathrm{C}$. A umidade relativa do ar é, aproximadamente, de 85\% (Almeida et al., 1993).

As coletas do material botânico foram realizadas em março, outubro e novembro de 2004, fevereiro de 2005 e janeiro de 2007. O trabalho consistiu em explorar (aleatoriamente) o maior número possível de micro-ambientes ocorrentes nos tipos de formações vegetacionais da área estudada, visando ao registro das espécies de monilófitas nessas formações, bem como na observação dos tipos de substratos das espécies. Primeiramente, foram exploradas as áreas de igarapés, dos igapós e várzeas e os seis plotes permanentes de 100 ha que fazem parte do Projeto TEAM (Tropical Ecology, Assessement and Monitoring) - Caxiuanã, além da Grade de 5 km² do Programa de Biodiversidade da Amazônia (PPBIO).

As amostras foram coletadas e herborizadas de acordo com a metodologia padrão para as plantas vasculares (Mori et al., 1989; Windisch, 1992). O material testemunho foi depositado no Herbário MG, do Museu Paraense Emílio Goeldi, com o envio de duplicatas como doação para vários Herbários do Brasil designados pelos acrônimos MBM, PACA, RB, SP e UB, segundo o Index Herbariorum (Holmgren et al., 1990).
A identificação do material botânico foi realizada mediante literatura especializada (Stolze, 1986; Tryon \& Stolze, 1993; Smith, 1995a, b).

A circunscrição aceita neste trabalho para as famílias e gêneros da linhagem Monilophyta segue Smith et al. (2006). Para o tratamento dos gêneros das famílias Cyatheaceae, Hymenophyllaceae e Thelypteridaceae, seguiram-se os seguintes autores, respectivamente: Lellinger (1987), Pryer et al. (2001) e Smith (1992). Para as licófitas, a circunscrição das famílias e gêneros foi realizada segundo Kramer \& Green (1990). Os termos "Lycophyta e Monilophyta" foram baseados em Pryer et al. (2004) para referir as linhagens que constituem o grupo das Pteridophytas.

A abreviatura dos nomes dos autores das espécies seguiu Pichi-Sermolli (1996). Os dados referentes à distribuição geográfica dos táxons foram baseados nas Floras do Equador (Stolze, 1986), do Peru (Tryon \& Stolze, 1994), da Guiana Venezuelana (Smith, 1995a, b) e Mesoamericana (Adams, 1995). A distribuição geográfica para os estados brasileiros foi baseada nos seguintes trabalhos: Bastos \& Cutrin (1999), Windisch \& Tryon (2001), Pietrobom \& Barros (2006) e Costa \& Pietrobom (2007).

\section{RESULTADOS E DISCUSSÃO}

Até o presente momento, foram registradas na FLONA de Caxiuanã 19 famílias, duas de Lycophyta e 17 de Monilophyta, que podem ser reconhecidas através da chave de identificação a seguir:

Chave para as famílias ocorrentes na FLONA de Caxiuanã

1. Folhas com uma única nervura, não fundidas formando bainha no nó; esporângios únicos localizados na axila do lado adaxial das folhas ou formando estróbilo no ápice dos ramos. (Lycophyta) 2 Folhas com venação ramificada, aberta ou areolada, raramente fundidas formando bainha no nó ou com projeções caulinares bífidas (enação); esporângios numerosos sobre a superfície abaxial da lâmina ou menos freqüentemente esporângios formando sinângio ou esporangióforos peltados agrupados em estróbilo (Monilophyta) 3

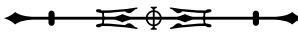


2. Plantas homosporadas; esporângios em estróbilos cilíndricos ou apenas um na axila das microfilas; microfilas estéreis monomórficas e geralmente todas similares e igualmente dispostas ao redor do caule

Lycopodiaceae

Plantas heterosporadas; esporângios em estróbilos aplainados ou quadrangulares; microfilas estéreis dimórficas, um tipo disposta em duas fileiras laterais e o outro disposta em duas fileiras dorsais Selaginellaceae

3. Plantas aquáticas flutuantes; esporângios em esporocarpos Salviniaceae Plantas terrestres, epíitas ou rupícolas; esporângios não inseridos em esporocarpos............................... 4

4. Esporângios reunidos em sinângios, desprovidos de ânulo; presença de estípulas recobrindo o caule e a base do pecíolo Marattiaceae Esporângios separados entre si, com ânulo em diferentes posições; sem estípulas no caule e na base do pecíolo.

5. Esporângios sésseis ou subsésseis; ânulo horizontal (lateral), apical ou oblíquo não interrompido pelo pedicelo 6

Esporângios pedicelados; ânulo vertical (longitudinal) interrompido pelo pedicelo .................................. 10

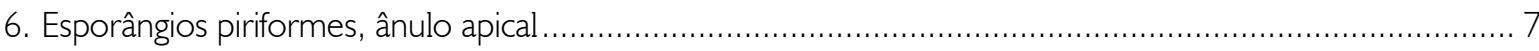

Esporângios globosos, ânulo oblíquo ......................................................................................... 8

7. Frondes trepadeiras, crescimento indeterminado; pinas bifurcadas, com gemas na bifurcação; cada esporângio protegido por um pseudoindúsio Lygodiaceae Frondes não trepadeiras, crescimento determinado; pinas não bifurcadas; esporângios sem indúsio, em 1 fileira de cada lado da nervura, agrupadas em esporangióforos pinados

Schizaeaceae

8. Lâmina membranácea; soros marginais; indúsio tubular, cônico ou bivalvado Hymenophyllaceae Lâmina cartácea a papirácea; soros abaxiais; indúsio globoso completo a escamiforme ou ausente 9

9. Plantas arborescentes; caule ereto, pecíolo com espinhos, escamas e tricomas ou somente com escamas; lâmina 1-2-pinado-pinatífida Cyatheaceae Plantas geralmente herbáceas; caule reptante a subereto, pecíolo sem espinhos e escamas, somente com tricomas; lâmina somente 1-pinada Metaxyaceae

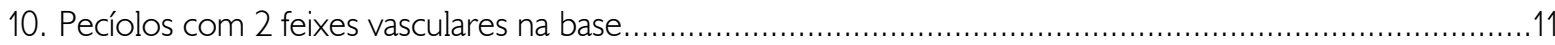

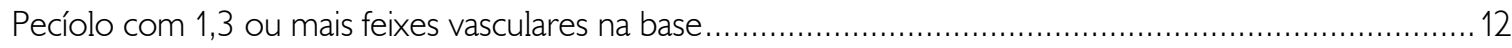

11. Indumento formado por tricomas unicelulares, aciculares, bifurcados ou estrelados; soros arredondados a alongados (não lineares) ou esporângios formando soros acrosticóides; escamas não clatradas Thelypteridaceae Indumento formado por tricomas pluricelulares; soros lineares; escamas clatradas .............. Aspleniaceae

12. Soros alongados a lineares, paralelos e adjacentes à costa Blechnaceae Soros arredondados; esporângios formando soros acrosticóides ou, se alongados ou lineares, oblíquos em relação à costa, ou paralelos e próximos da margem da lâmina

13. Caule reptante com duas fileiras de frondes no lado dorsal do caule; pecíolo articulado ao caule; lâmina geralmente pinatisecta a 1-pinada, inteira ou subdicotomicamente furcada Polypodiaceae

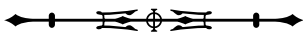


Caule ereto a reptante, geralmente com frondes dispostas em espiral no caule; pecíolo não articulado ao caule ou às vezes; lâmina inteira até 5 -pinada ou raramente furcada

14. Lâmina inteira a pinatífida ou mais raramente furcada na porção apical ou, apenas 1-pinada com pinas não dimidiadas

15. Esporos triletes com clorofila Polypodiaceae (gêneros gramitióides)

Esporos triletes ou monoletes sem clorofila

16. Frondes 1-pinadas. Lomariopsidaceae

Frondes inteiras ou raramente furcadas na porção apical

17. Soros acrosticóides; frondes dimórficas Dryopteridaceae (gênero Elaphoglossum)

Soros lineares a alongados ou arredondados; frondes monomórficas. 18

18. Soros lineares a alongados; indúsio ausente; pecíolo não articulado ao caule Pteridaceae (gêneros vitarióides)

Soros arredondados; indúsio orbicular, semilunar, reniforme ou orbicular-reniforme; pecíolo articulado ao caule Oleandraceae

19. Soros lineares, abaxiais ou marginais a submarginais ...... 20 Soros arredondados ou acrosticóides. 21

20. Indúsio verdadeiro presente, abrindo-se em direção à margem (extrorso). Lindsaeaceae Indúsio verdadeiro ausente, freqüentemente protegido pela margem do segmento reflexo (pseudoindúsio) ou ausente Pteridaceae

21. Raque, costa e cóstula conspicuamente sulcadas adaxialmente, sulcos decorrentes entre si; indúsio peltado ou ausente Dryopteridaceae Raque, costa e cóstula não sulcadas adaxialmente ou levemente sulcadas, sulcos não decorrentes entre si; indúsio circular-reniforme Tectariaceae

\section{Aspleniaceae Newman}

Família monofilética, com distribuição quase cosmopolita, comum nos trópicos e subtrópicos, com apenas um gênero Asplenium L. (Smith et al., 2006).

\section{Asplenium L., Sp. Pl. 2: 1078. 1753.}

Plantas terrestres, epífitas ou rupícolas. Caule curtoreptante, ascendente ou subereto, robusto a delgado, glabro ou com escamas clatradas, iridescentes, inteiras, raramente com tricomas. Frondes monomórficas, fasciculadas a espaçadas; pecíolos com escamas na base (algumas vezes outros eixos), usualmente glabros; lâmina inteira ou lobada, freqüentemente 1-2-pinada, ocasionalmente mais dividida a 4-pinada, truncada na base, usualmente sem tricomas ou várias espécies com tricomas diminutos ou escamas reduzidas no lado abaxial; raque freqüentemente alada, levemente sulcada adaxialmente, sulcos interrompidos a unidos com a pina lateral, margem inferior da pina decurrente na raque; pinas freqüentemente desiguais, escavadas no lado proximal, comumente truncadas, anguladas ou auriculadas no lado distal; venação livre, furcada ou não, raramente anastomosada, as aréolas sem vênulas inclusas. Soros alongados a lineares, ao longo do lado acroscópico da vênula; indúsio ao longo do soro, ou raramente sobre uma bolsa quase marginal formada pelo indúsio e tecido laminar adjacente; esporos monoletes, sem clorofila.

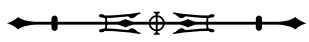


Asplenium apresenta distribuição cosmopolita, com cerca de 700 espécies predominantemente tropicais (Mickel \& Smith, 2004). Destas, 72 espécies (incluindo Antigramma
C. Presl) ocorrem no Brasil (Sylvestre \& Ramos, 2005); no estado do Pará, são conhecidas para o gênero 20 espécies e, na FLONA de Caxiuanã, foram registradas três espécies.

Chave para as espécies de Asplenium L. da FLONA de Caxiuanã

1. Fronde pinada; base da pina cuneada, o lado acroscópico levemente arredondado, margem inteira a levemente crenada A. juglandifolium

Fronde inteira..... 2

2. Lâmina 1-3,5(4-) cm de largura, linear-lanceolada, longamente atenuada em direção a base e ápice; vênulas secundárias em ângulo de $45-65^{\circ}$ com a costa......

A. angustum Lâmina 4-12,5 cm de largura, lanceolada, ápice obtuso a agudo, às vezes caudado, base atenuadamente cuneada; vênulas secundárias em ângulo de $20^{\circ}-40^{\circ}\left(-45^{\circ}\right)$ com a costa.

A. serratum

\section{Asplenium angustum Sw., Kongl. Vetensk. Acad. Handl. 38: 66, t. 4. fig. 1. 1847. (Figura 1)}

Plantas epífitas. Caule ereto, escamas linear-lanceoladas, castanho-escuras a nigrescentes, margem inteira, fimbriadas na base, ápice acuminado, uniseriado; frondes $15-48 \mathrm{~cm}$ de comprimento, inteiras, eretas, fasciculadas, 6-8 por caule; pecíolo curto, 2-3 cm de comprimento, castanho a paleáceo, sulcado na face adaxial, alado na porção distal pela base da lâmina decurrente, com escamas esparsas, nigrescentes; lâmina 15-45 cm de comprimento, 1-3,5(-4) cm de largura, inteira, linear-lanceolada, cartácea, longamente atenuada em direção à base e ápice, margem inteira a sinuosa; raque castanha na face adaxial, especialmente na porção proximal da lâmina, com escamas esparsas, castanho-claras a nigrescentes; venação simples ou 1-furcada, vênulas secundárias partindo da costa em ângulo de $45^{\circ}-65^{\circ} \mathrm{com}$ a costa, mais evidentes no lado abaxial; soros 50-100 por lâmina, ao longo das vênulas, lineares; indúsio da mesma cor da lâmina, margem inteira, cerca de 0,5 mm de largura.

Asplenium angustum caracteriza-se pela lâmina longamente atenuada em direção à base e ápice e vênulas secundárias em ângulo de $45^{\circ}-65^{\circ}$ com a costa. Smith (1995a) comenta que muitos espécimes identificados como A. angustum em herbário são, provavelmente, somente formas mais estreitas de $A$. serratum $L$.
Planta pouco comum na área, observada em floresta de terra firme, crescendo na base de tronco vivo ou sobre galhos.

Distribuição neotropical, restrita para a América do Sul, com registros na Guiana, Guiana Francesa, Suriname, Venezuela, Colômbia, Peru e Bolívia. No Brasil, é citado no Amapá, Amazonas, Pará, Acre e Rondônia.

Material examinado: Brasil, Pará: município Melgaço, Estação Cientíica Ferreira Penna, atrás da base física da ECFPn, trilha para a torre de 55 m do Projeto Grande Escala da Biosfera-Atmosfera na Amazônia (LBA), 31/10/2004, Sanjuan \& Pietrobom 205 (MG); município Melgaço/Portel, Floresta Nacional de Caxiuanã, grade do Programa de Pesquisa em Biodiversidade (PPBio), linha A, ca. 1 ${ }^{\circ} 57$ '36"S51936'55”W, 21/01/2007, Pietrobom et al. 6397 (MG).

\section{Asplenium juglandifolium Lam., Encycl. 2: 307. 1786. (Figura 2)}

Plantas epífitas. Caule curto-reptante a subereto, escamas filiformes, castanho-escuras, margem inteira, uniseriada e contorcida na extremidade. Frondes $16-48 \mathrm{~cm}$ de comprimento, arqueadas, fasciculadas, 2-4 por caule; pecíolo (6,5-)11-13 cm de comprimento, castanhoesverdeado, sulcado e achatado na face abaxial, alado na porção distal, com escamas semelhantes as do caule;

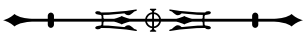




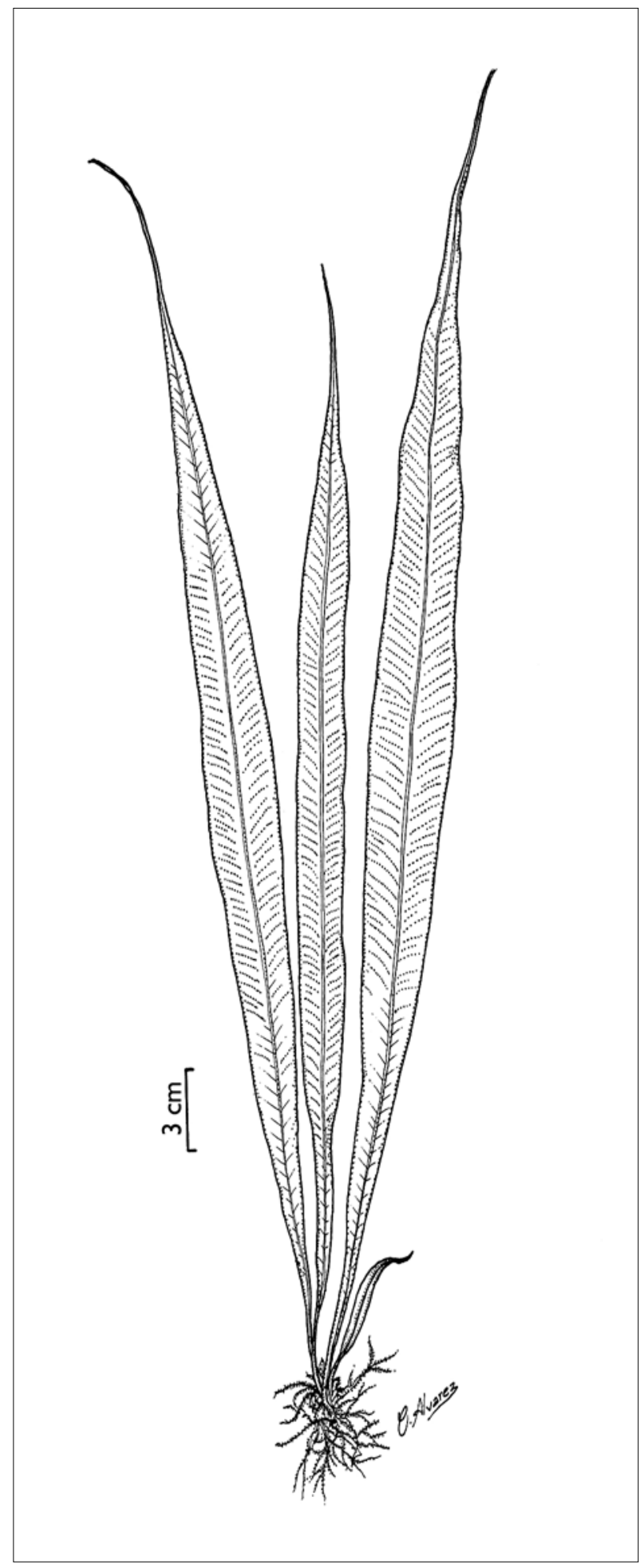

Figura 1. Asplenium angustum Sw.: Hábito (Sanjuan \& Pietrobom 205). lâmina (16-) 25-31 cm de comprimento, $8-17 \mathrm{~cm}$ de largura, 1-pinada, cartácea, deltado-ovada, ápice agudo, não pinatííido, pina terminal conforme, base truncada; raque pálea a castanho-clara ou esverdeada, glabra, achatada ou angulosa, alada mais visível na porção distal; pinas (6,5-)9-11 cm de comprimento, 1,7-2 cm de largura, lanceoladas a falcadas, (3-)4-9 pares, afastadas, longo acuminadas, margem inteira ou levemente crenada, base cuneada, assimétrica, lado acroscópico levemente arredondado, ápice atenuado, indumento no lado adaxial com tricomas clavados, espalhados, adpressos, esbranquiçados a castanho-claros; venação imersa, livre, 1-2-furcada, vênula partindo da costa $60^{\circ}-65^{\circ}$, evidente na superfície adaxial; soros lineares, 7-14 pares por pinas, ao longo das vênulas; indúsio mais escuro que a lâmina, margem inteira, ca. 0,8-1 mm de largura.

Asplenium juglandifolium é a única espécie da família registrada, até o presente estudo, que possui frondes 1-pinadas, as demais espécies possuem frondes inteiras. Prado (2005a) comenta que varia o número de pares de pinas por fronde (7-12 pares) registrado na Flora da Reserva Ducke. No material registrado na FLONA de Caxiuanã, ocorre de (3-)5-7 pares por fronde.

Planta com poucos indivíduos, observada na floresta de terra firme ou de igapó, crescendo na base de tronco vivo.

Distribuição neotropical, com registros no México, América Central, Caribe (Grandes Antilhas e Trinidad), Guiana, Guiana Francesa, Suriname, Venezuela, Colômbia, Equador, Peru, Bolívia e Brasil (Amapá, Amazonas, Pará, Acre e Rondônia).

Material examinado: Brasil, Pará: município Melgaço, Estação Científica Ferreira Penna, plote 6 de 100 ha do Projeto Tropical Ecology Assessment and Monitoring (TEAM), 05/11/2004, Sanjuan \& Pietrobom 349 (MG); ibid., plote 3 de 100 ha do Projeto TEAM, 20/11/2004, Sanjuan \& Pietrobom 599 (MG, RB); ibid., próximo do igarapé Sapucuzinho, 04/03/2005, Pietrobom 5835 (MBM, MG, RB); município Melgaço/Portel, Floresta Nacional de Caxiuanã, grade do PPBio, linha D, parcela 19, ca. 


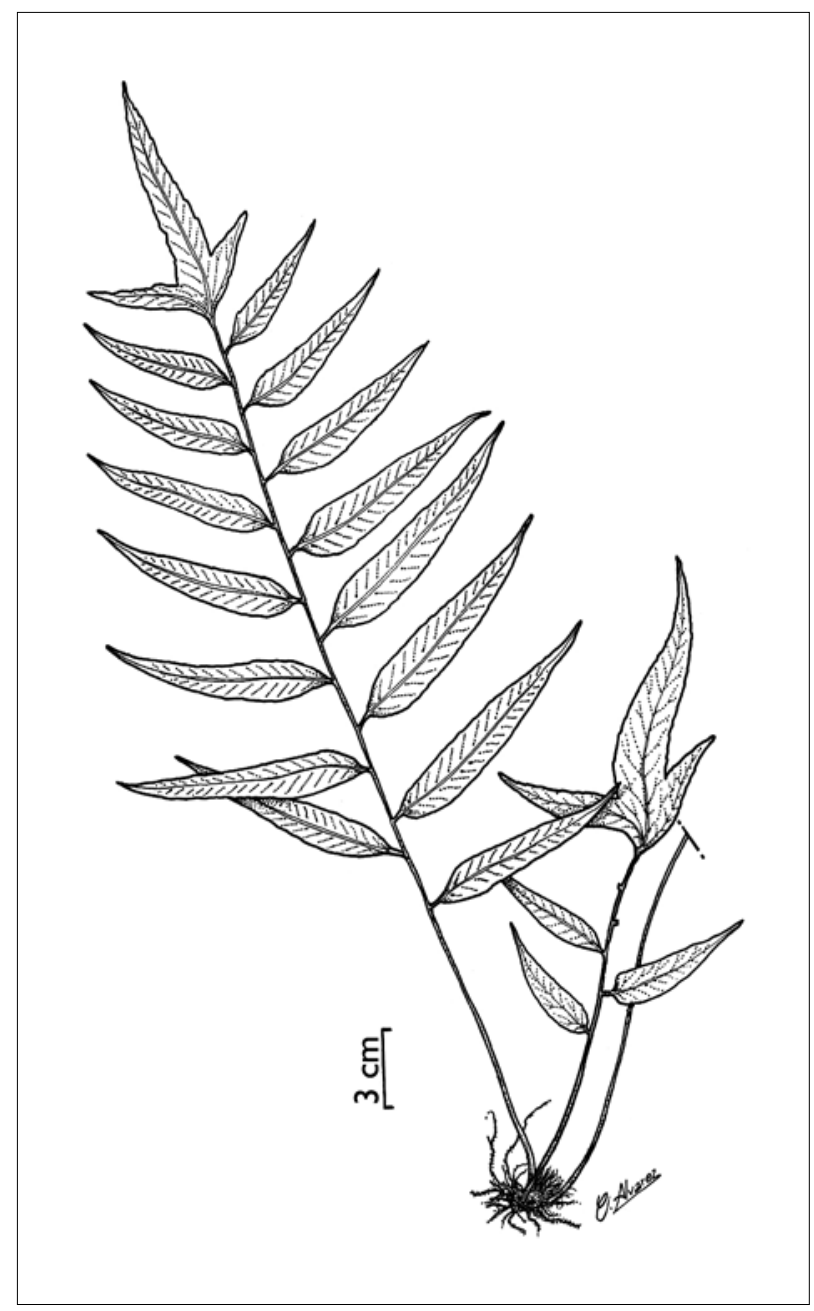

Figura 2. Asplenium juglandifolium Lam.: Hábito (Pietrobom 5835).

159'14,4"-51938'48,4”W, 15/01/2007, Pietrobom et al. 6659 (MG, MBM, RB).

\section{Asplenium serratum L., Sp. Pl. 2: 1079. 1753.}

(Figura 3)

Plantas epífitas. Caule ereto, com escamas lanceoladas, castanho-escuras, margem inteira, com extremidade atenuada ou filiforme. Frondes 15-104 cm de comprimento, inteiras, eretas, fasciculadas, 5-20 por caule; pecíolo 2-4 cm de comprimento, castanho-escuro a negro ou esverdeado, achatado e sulcado na face adaxial, alado, glabro; lâmina 15-100 cm de comprimento, 4-12,5 cm de largura, inteira,

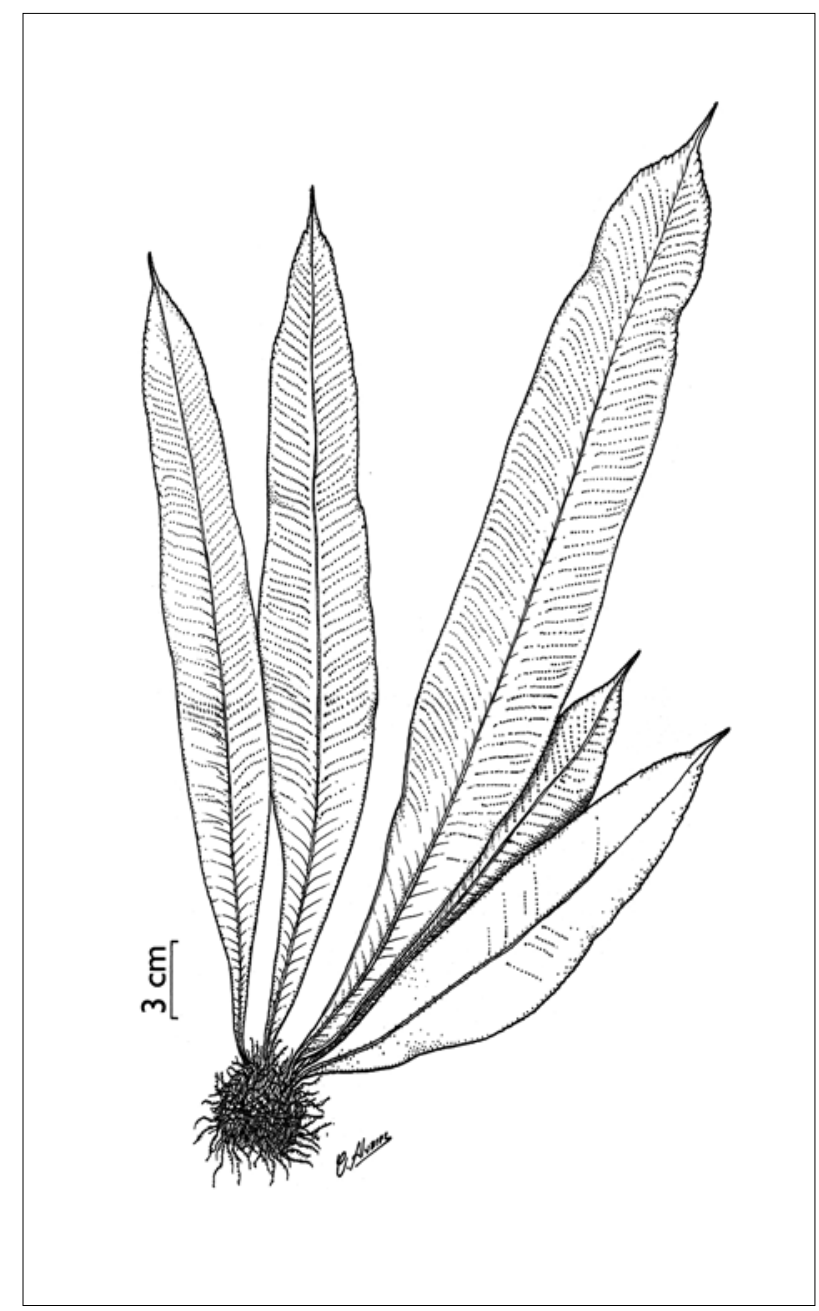

Figura 3. Asplenium serratum Sw.: Hábito (Sanjuan \& Pietrobom 133).

estreitamente oblanceolada, cartácea, ápice obtuso a agudo, às vezes caudado, base atenuadamente cuneada, margem inteira a crenulada a serreada; raque esverdeada a nigrescente, com escamas esparsas, castanho-escuras; venação simples ou 1-furcada, vênulas secundárias em ângulo de $20^{\circ}-40^{\circ}\left(-45^{\circ}\right)$ com a costa, usualmente visíveis em ambos os lados; soros + 100 por lâmina, ao longo das vênulas, lineares, formando uma faixa contínua mais próxima da costa, nunca atingindo a margem; indúsio esbranquiçado, margem inteira, linear, ca. $1 \mathrm{~mm}$ de largura.

Asplenium serratum, quando jovem, pode ser confundido com $A$. angustum por apresentar frondes com 
lâminas atenuadas em direção à base e ápice. Entretanto, A. serratum apresenta lâmina com ápice obtuso a agudo, às vezes caudado, base atenuadamente cuneada e as vênulas secundárias em ângulo de $20^{\circ}-40^{\circ}\left(-45^{\circ}\right)$ com a costa, enquanto que $A$. angustum possui lâmina mais estreita, 1$3,5(-4) \mathrm{cm}$ de largura, base e ápice longamente atenuada e vênulas em ângulo de $45^{\circ}-65^{\circ}$ com a costa.

Planta muito comum na área, observada no interior da floresta de terra firme, de igapó e em capoeiras, crescendo na base de troncos vivos.

Distribuição neotropical, com registros nos Estados Unidos da América (Flórida), sul do México, América Central, Caribe (Antilhas e Trinidad), Guiana, Guiana Francesa, Suriname, Venezuela, Colômbia, Equador, Peru, Bolívia, Paraguai e norte da Argentina. No Brasil, é citado em Roraima, Amapá, Amazonas, Pará, Acre, Rondônia, Mato Grosso, Mato Grosso do Sul, Goiás, Maranhão, Ceará, Paraíba, Pernambuco, Alagoas, Bahia, Minas Gerais, Espírito Santo, Rio de Janeiro, São Paulo, Paraná e Santa Catarina.

Material examinado: Brasil, Pará: município Melgaço, Estação Científica Ferreira Penna, igarapé do Laranjal, limite da FLONA de Caxiuanã, 28/10/2004, Sanjuan 182 (MG, RB, UB); ibid., atrás da base física da ECFPn, trilha para a torre de $55 \mathrm{~m}$ do Projeto LBA, 31/10/2004, Sanjuan \& Pietrobom 223 (MG, RB, UB); ibid. , trilha para o plote 6 de 100 ha do Projeto TEAM, 05/10/2004, Sanjuan \& Pietrobom 337 (MBM, MG, RB); ibid., plote 2 de 100 ha do Projeto TEAM, 08/10/2004, Sanjuan \& Pietrobom 432 (MBM, MG); ibid., plote 3 de 100 ha do Projeto TEAM, 20/11/2004, Sanjuan \& Pietrobom 621 (MG); ibid., margem do igarapé Caxiuanã, 04/03/2005, Pietrobom 5829 (MBM, MG); município Melgaço, Caxiuanã, saída do refeitório para o campo de futebol da ECFPn, 08/03/2004, Freitas 1039 (MG); município Melgaço/Portel, Floresta Nacional de Caxiuanã, grade do PPBio, linha $\mathrm{C}$, parcela 14, ca. $1^{\circ} 58^{\prime}, 41,9^{\prime \prime} \mathrm{S}-51^{\circ} 38^{\prime} 48,4^{\prime \prime} \mathrm{W}, 14 / 01 / 2007$, Pietrobom et al. 6582 (MG, RB).

\section{Blechnaceae Newman}

Família monofilética, subcosmopolita, com 200250 espécies, em aproximadamente nove gêneros (Smith, 1995b; Smith et al., 2006), dos quais somente três ocorrem nas Américas, Salpichlaena Hook. exclusivamente neotropical, Woodwardia Sm. chegando até a América Central e Blechnum L. de ampla distribuição (Tryon \& Tryon, 1982), e cerca de 200 espécies (Smith et al., 2006). Na flora do estado do Pará e na FLONA de Caxiuanã, foram registrados dois gêneros, Blechnum e Salpichlaena.

Chave para os gêneros de Blechnaceae da FLONA de Caxiuanã

1. Frondes de crescimento determinado, não trepadeiras; raque rugosa; lâminas simples a 1-pinadas Blechnum

Frondes de crescimento indeterminado, trepadeiras; raque entrelaçada a escandente; lâminas 2-pinadas Salpichlaena

\section{Blechnum L., Sp. Pl. 2: 1077. 1753.}

Plantas terrestres, raro rupícolas, ocasionalmente hemiepífitas ou subarborescentes. Caule longo-reptante, compacto a ereto, ocasionalmente escandente, às vezes formando tronco, ramificado ou não, estoloníferos em algumas espécies, com escamas castanhas. Frondes monomórficas a fortemente dimórficas, as férteis usualmente maiores que as estéreis e com segmentos mais estreitos; báculos algumas vezes cobertos com mucilagem e apresentando aeróforos semelhantes a escamas ou tuberculiformes ao longo do pecíolo e na base da pina; pecíolo adaxialmente sulcado; lâminas usualmente 
pinatífidas ou 1-pinadas (raramente inteiras ou 2-pinadas); pinas inteiras ou serruladas, com escamas, tricomas ou glabras sobre o eixo; venação furcada, livre, \pm paralela ou anastomosada, sem vênula livre inclusa. Soros lineares, sobre uma comissura vascular paralela à costa; indúsio linear, fixo à comissura e abrindo em direção à costa, firme, inteiro, a eroso ou lacerado, especialmente na maturidade; esporos monoletes sem clorofila.

Blechnum apresenta distribuição pantropical (principalmente no Hemisfério Sul, incluindo as regiões temperadas do sul, com uma única espécie estendendo-se às regiões temperadas do Hemisfério Norte), com cerca de 200 espécies (Mickel \& Smith, 2004; Smith, 1995b). Na flora do estado do Pará, são conhecidas para o gênero quatro espécies e, na FLONA de Caxiuanã, foi registrada apenas Blechnum serrulatum Rich.

\section{Blechnum serrulatum Rich., Actes Soc. Hist. Nat. Paris 1: 114. 1792. (Figura 4A)}

Plantas terrestres. Caule longo-reptante, subterrâneo, com escamas linear-lanceoladas, castanhas ou negras, margens inteiras. Frondes $40-90 \mathrm{~cm}$ de comprimento, monomórficas a levemente dimórficas, fasciculadas, eretas; pecíolos 14-34 cm de comprimento, com a porção distal sulcada, glabros ou a base com escamas semelhantes às do caule; lâminas foliares 40-60 cm de comprimento, (5-)11-18 cm de largura, 1-pinadas, oblongas a lanceoladas, cartáceas a subcoriáceas, pina terminal conforme a sub-conforme, base truncada e sem pina vestigial, glabra; raque pálea a castanho-claras, adaxialmente sulcada, glabra; pinas (3-)5$10,5 \mathrm{~cm}$ de comprimento, 0,7-1,4 cm de largura, $12-25$ pares, lineares ou lineares oblongas, curto-pecioluladas ou sésseis, nunca adnadas, eqüilaterais, articuladas a raque e decíduas, margens cartilaginosas, serreadas, não revolutas, ápice agudo a acuminado, abaxialmente com escamas castanho-claras na costa, adaxialmente glabras; vênulas 1-2-furcadas; soros lineares, paralelos, adjacentes à costa; indúsio inteiro a eroso, abrindo-se em direção à costa; esporângios persistentes, às vezes encobrindo a costa.
Blechnum serrulatum é a única espécie do gênero que ocorre nos neotrópicos a apresentar pinas articuladas com a raque (Moran, 1995).

Planta comumente encontrada em área alagada, sobre as raízes de outros vegetais.

Distribuição pantropical, com registro na Malásia, Austrália, Estados Unidos da América (sul da Flórida), México, América Central, Caribe (Antilhas e Trinidad), Guiana, Guiana Francesa, Suriname, Venezuela, Colômbia, Equador, Peru, Bolívia, Paraguai, norte da Argentina e Brasil (Roraima, Amapá, Amazonas, Pará, Rondônia, Maranhão, Alagoas, Mato Grosso, Mato Grosso do Sul, Goiás, Distrito Federal, Piauí, Paraíba, Pernambuco, Bahia, Minas Gerais, Espírito Santo, Rio de Janeiro, São Paulo, Paraná, Santa Catarina e Rio Grande do Sul).

Material examinado: Brasil, Pará: município Melgaço, Estação Científica Ferreira Penna, igarapé Curuazinho, 27/10/2004, Sanjuan 177 (MG, MBM, RB, UB); ibid., igarapé do Laranjal, limite da FLONA de Caxiuanã, 27/10/2004, Sanjuan \& Pietrobom 185 (MG, SP, PACA); ibid., igarapé Puraquequara, 02/03/2005, Pietrobom 5805 (MBM, MG, PACA, UB).

\section{Salpichlaena Hook., Gen. Fil. t. 93. 1842.}

Plantas terrestres. Caule longo-reptante, escamoso, as escamas pequenas, rígidas, castanho-escuro a nigrescentes. Frondes monomórficas ou dimórficas; raque entrelaçado e escandente até $15 \mathrm{~m}$; lâminas foliares 2-pinadas, as juvenis simples a trifolioladas; pinas distantes, opostas ou subopostas, longo-pecioladas, glabras abaxialmente ou escamosas no eixo, algumas vezes com tricomas; pínulas linear-elípticas ou linearlanceoladas, inteiras, serreadas no ápice, as estéreis com margem cartilaginosa; venação simples ou 1furcada próximo da base, extremidades conectadas por uma vênula marginal. Soros decíduos, deixando a pínula aparentemente estéril, lineares, em uma longa comissura vascular paralela próximo à costa; indúsio decíduo, linear, castanho-escuro, abrindo-se em direção 
à costa, reflexo e fragmentado na maturidade; paráfises ausentes; esporos monoletes, sem clorofila.

Gênero com distribuição neotropical e somente três espécies (Moran, 1995). Na flora do estado do Pará, são conhecidas, para o gênero, apenas duas espécies, e, na FLONA de Caxiuanã, foi registrada apenas Salpichlaena hookeriana (Kuntze) Alston.

\section{Salpichlaena hookeriana (Kuntze) Alston, Bull. Misc.} Inform. 1932: 312. 1932. (Figura 4B-D)

Blechnum volubile var. lomarioidea Baker in Mart., Fl. Bras. 1(2): 428. 1870.

Salpichlaena laminarioidea (Baker) A.R. Sm., Ann. Missouri Bot. Gard. 77: 250. 1990.

Plantas terrestres. Caule longo-reptante, com escamas lanceoladas, castanho-claras a castanho-escuras. Frondes dimórficas, longo-trepadeiras; pecíolo paleáceo, achatado; lâminas foliares estéreis 2-pinadas, cartáceas a subcoriáceas, margens cartilaginosas, glabras; raque paleácea, longo-escandente, glabra; pinas (28-)34-77 $\mathrm{cm}$ de comprimento, 35-60 cm de largura, 1-pinadas, gemas presentes na axila de algumas pinas basais; pínulas 17-30 cm de comprimento, 3,5-6,5 cm de largura, 2-6 pares, inteiras, elípticas, subopostas, longo-pecioluladas, base arredondada, levemente inequilateral, ápice agudo, margem inteira nas regiões basal e mediana e serreada na região apical, com escamas sobre a costa abaxialmente; lâminas foliares férteis 2-pinadas; pinas férteis na extremidade da lâmina; pínulas $18-30 \mathrm{~cm}$ de comprimento, 0,2-0,5 cm de largura, 3-6 pares, inteiras, lineares, subopostas, pecioluladas; esporângios facilmente decíduos.

Salpichlaena hookeriana tem sido sinonimizada em S. volubilis (Kaulf.) J. Sm., sendo que, segundo Tuomisto \& Groot (1995), há diferenças morfológicas significativas que podem sustentar a separação em dois táxons distintos. S. hookeriana possui frondes fortemente dimórficas, com as pinas férteis na extremidade da lâmina e gemas presentes na axila de algumas pinas basais estéreis, enquanto que

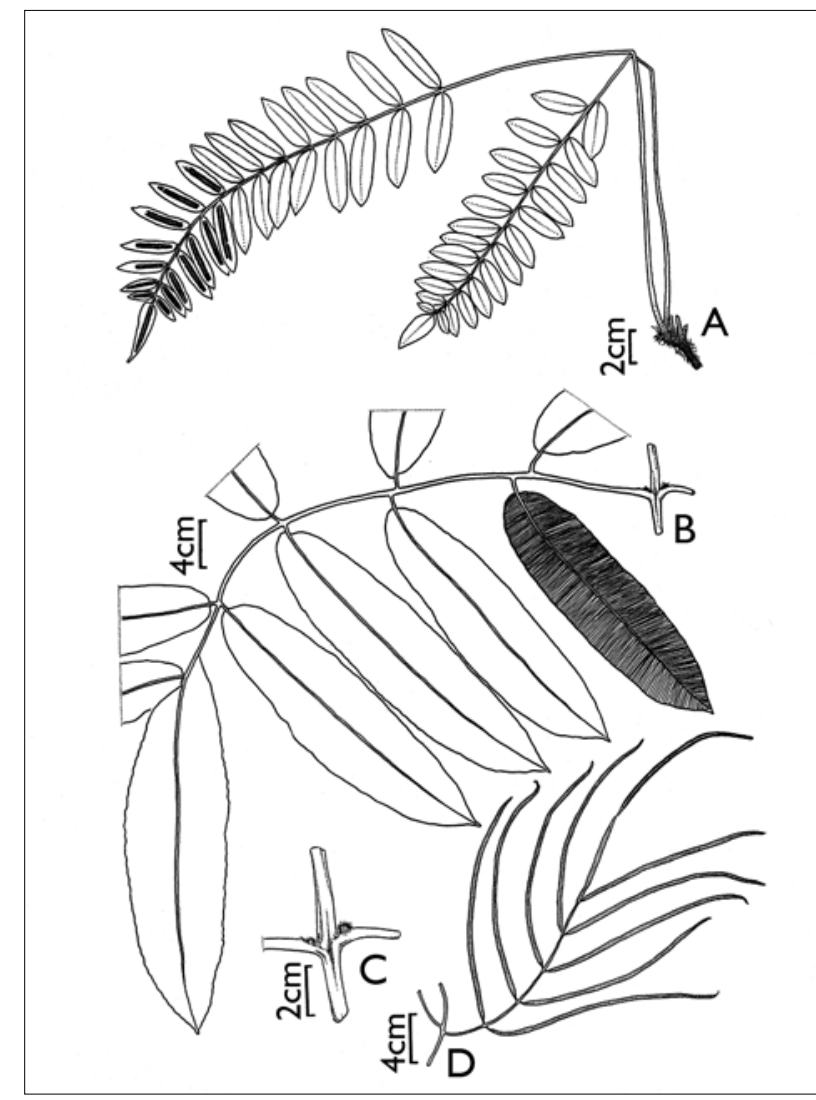

Figura 4. A. Blechnum serrulatum Rich: Hábito (Sanjuan 177). B-D. Salpichlaena hookeriana (Kuntze) Alston. B. pina estéril; C. parte da raque evidenciando gema na base do pecíolo da pina; $D$. pina fértil (Pietrobom et al. 6326).

S. volubilis (Kaulf.) J. Sm. possui frondes monomórficas e pinas férteis comumente na maior parte da lâmina e gemas ausentes na axila das pinas.

Planta observada sempre em florestas de igapó, em ambiente sempre encharcado.

Distribuição neotropical, restrita para a América do Sul, com registros na Guiana, Guiana Francesa, Suriname, Colômbia, Peru e Brasil (Amazonas e Pará).

Material examinado: Brasil, Pará: município Melgaço, Estação Científica Ferreira Penna, plote 2 de 100 ha do Projeto TEAM, 08/11/2004, Sanjuan \& Pietrobom 398 (MG, MBM, SP, RB); ibid., plote 1 de 100 ha do Projeto TEAM, 09/11/2004, Sanjuan \& Pietrobom 543 (MBM, MG, PACA, RB, SP); ibid., próximo do igarapé Puraquequara, 
28/02/2005, Pietrobom 5790 (MG, RB); ibid., atrás da base física da ECFPn, igarapé Puraquequara, 03/11/2004, Sanjuan 290 (MG); município Melgaço/Portel, Floresta Nacional de Caxiuanã, grade do PPBio, linha B, ca. 1950'09"S-51³6'55"W, 13/01/2007, Pietrobom et al. 6326 (MG, RB, SP, UB, PACA); ibid., grade do PPBio, linha C, ca. 156'41,9”S-51³6'55”W, 13/01/2007, Pietrobom et al. 6338 (MG, RB).

\section{AGRADECIMENTOS}

Os autores agradecem ao Dr. Michael Hopkins pela elaboração do Abstract.

\section{REFERÊNCIAS}

ADAMS, C. D., 1995. Asplenium L. In: R. C. MORAN \& R. RIBA (Eds.): Flora Mesoamericana 1. Psilotaceae a Salviniaceae: 290-324. Universidad Nacional Autónoma de México, México.

ALMEIDA, S. S., G. O. RIBEIRO, J. M. PIRES, P. L. B. LISBOA \& A. S. L. SILVA, 1997. Abundância, riqueza e similaridade em duas florestas de terra firme da Amazônia Oriental. In: P. L. B. LISBOA (Ed.): Caxiuanã: 263-271. Museu Paraense Emílio Goeldi, Belém.

ALMEIDA, S. S., P. L. B. LISBOA \& A. S. L. SILVA, 1993. Diversidade florística de uma comunidade arbórea da Estação Científica Ferreira Penna, em Caxiuanã (Pará). Boletim do Museu Paraense Emílio Goeldi, série Botânica 9(1): 93-188.

BASTOS, C. C. C. \& M. V. J. CUTRIM, 1999. Pteridoflora da Reserva Florestal do Sacavém, São Luiz - Maranhão. Boletim do Museu Paraense Emílio Goeldi, série Botânica 15(1): 3-37.

BRASIL. Decreto n²39, de 28 de novembro de 1961. Cria a Floresta Nacional de Caxiuanã e dá outras providências. Diário Oficial da União. Brasília, DF, 30 nov. 1961.

COSTA, J. M. \& M. R. PIETROBOM, 2007. Pteridófitas (Lycophyta e Monilophyta) da Ilha de Mosqueiro, município de Belém, Estado do Pará, Brasil. Boletim do Museu Paraense Emílio Goeldi. Ciências Naturais 2(3): 45-56.

COSTA, J. M., M. R. PIETROBOM \& M. G. C. SOUZA, 2006. Primeiro registro de Trichomanes pinnatinervium Jenman (Hymenophyllaceae - Monilophyta) para o Brasil. Bradea 11: 33-36.

HOLMGREN, P. K., N. H. HOLMGREN \& L. BARNETT, 1990. Index herbariorum. Part 1: The herbaria of the world. 8 ed. New York Botanical Garden, New York.
HUBER, J., 1906. Vegetação na beira d'um igarapé d'água preta de Bragança. In: J. HUBER. Arboretum Amazonicum: 1-4: 40. Museu Paraense Emílio Goeldi, Belém.

HUBER, J., 1902. Materiais para a Flora Amazônica. V. Plantas Vasculares colhidas ou observadas na região dos furos de Breves em 1900 e 1901. Boletim do Museu Paraense Emílio Goeldi 3: $400-406$

HUBER, J., 1898. Materiais para a Flora Amazônica. I. Lista das plantas coligidas da ilha de Marajó no ano de 1896. Boletim do Museu Paraense Emílio Goeldi 1-4: 288-322.

IBGE, 1981. Sinopse preliminar do censo demográfico: Pará: 1(5): 1-46. IBGE, Rio de Janeiro.

KRAMER, K. U. \& P. S. GREEN, 1990. Pteridophytes and Gymnosperms. The families and genera of vascular plants 1: 1-404. Springer-Verlag, Berlin.

LELLINGER, D. B., 1987. The disposition of Trichipteris (Cyatheaceae). American Fern Journal 77: 90-94.

LISBOA, P. L. B. (Ed.), 1997a. Caxiuanã: 1-446. Museu Paraense Emílio Goeldi, Belém.

LISBOA, P. L. B., 1997b. A Estação Científica Ferreira Penna/ECFPn. In: P. L. B LISBOA (Ed.): Caxiuanã: 23-49. Museu Paraense Emílio Goeldi, Belém.

LISBOA, R. C. L. \&J. M. M. NAZARÉ, 1997. A Flora Briológica. In: P. L. B. LISBOA (Ed.): Caxiuanã: 221-233. Museu Paraense Emílio Goeldi, Belém.

LISBOA, P. L. B., A. S. L. SILVA \& S. S. ALMEIDA, 1997. Florística e Estrutura dos Ambientes. In: P. L. B LISBOA (Ed.): Caxiuanã: 163-193. Museu Paraense Emílio Goeldi, Belém.

LUIZI-PONZO, A. P., O. M. BARTH \& R. C. L. LISBOA, 1997. Estudos Palinológicos em Briófitas. In: P. L. B. LISBOA (Ed.): Caxiuanã: 305-318. Museu Paraense Emílio Goeldi, Belém.

MICKEL, J. T. \& A. R. SMITH, 2004. The Pteridophytes of Mexico. Memoirs New York Botanical Garden 88: 1-1055.

MONTAG, L. F. A., T. M. S. FREITAS, W. B. WOSIACKI \& R. B. BARTHEM, 2008. Os peixes da Floresta Nacional de Caxiuanã (municípios de Melgaço e Portel, Pará - Brasil). Boletim do Museu Paraense Emílio Goeldi. Ciências Naturais 3(1): 11-34.

MORAN, R. C., 1995. Blechnaceae. In: R. C. MORAN \& R. RIBA (Eds.): Flora Mesoamericana 1. Psilotaceae a Salviniaceae: 325333. Universidad Nacional Autónoma de México, México.

MORI, S. A., L. A. M. SILVA, G. LISBOA \& L. CORADIN, 1989. Manual de manejo do herbário fanerogâmico: 1-104. Centro de Pesquisa do Cacau, Ilhéus. 
PICHI-SERMOLLI, R. E. G., 1996. Authors of Scientifc names in Pteridophyta: 1-78. Royal Botanical Garden, Kew.

PIETROBOM, M. R. \& I. C. L. BARROS, 2006. Associações entre as espécies de pteridófitas em dois fragmentos de Floresta Atlântica do Nordeste Brasileiro. Biotemas 19(3): 15-26.

PIETROBOM, M. R. \& I. C. L. BARROS, 2001. Aspleniaceae (Pteridófita) da Mata do Estado, município de São Vicente Férrer, Pernambuco, Brasil. Leandra 16: 39-49.

PRADO, J., 2005a. Flora da Reserva Ducke, Amazonas, Brasil: Pteridophyta - Aspleniaceae. Rodriguésia 56(86): 29-32.

PRADO, J., 2005b. Flora da Reserva Ducke, Amazonas, Brasil: Pteridophyta - Blechnaceae. Rodriguésia 56(86): 33-34.

PRADO, J., 2004. Criptógamos do Parque Estadual das Fontes do Ipiranga, São Paulo, SP. Pteridophyta: chave para as famílias; 2. Blechnaceae. Hoehnea 31(1): 1-10.

PRADO, J., 2003. Revisões e monografias como base para análise da diversidade, o quanto conhecemos sobre a nossa flora. In: $M$. A. G. JARDIM, M. N. C. BASTOS \& J. U. M. SANTOS (Eds.): Desafios da Botânica Brasileira no Novo Milênio: inventário, sistematização e conservação da diversidade vegetal: 278-279. MPEG/UFRA/EMBRAPA, Belém.

PRYER, K. M., E. SCHUETTPELZ, P. G. WOLF, H. SCHNEIDER, A. R. SMITH \& R. CRANFILL, 2004. Phylogeny and evolution of ferns (Monilophytes) with a focus on the early leptosporangiate divergences. American Journal of Botany 91(10): 1582-1598.

PRYER, K. M., H. SCHNEIDER, A. R. SMITH, R. CRANFILL, P. G. WOLF, J. S. HUNT \& S. D. SIPES, 2001. rbcL data reveal two monophyletic groups of filmy ferns (Filicopsida: Hymenophyllaceae). Amererican Journal of Botany 88: 1118-1130.

RODRIGUES, S. T., S. S. ALMEIDA, L. H. C. ANDRADE, I. C. L. BARROS \& M. E. VAN DEN BERG, 2004. Composição florística e abundância de pteridófitas em três ambientes da bacia do rio Guamá, Belém, Pará, Brasil. Acta Amazônica 34(1): 35-42.

SAMPAIO, A. J., 1930. Eufilicíneas do Rio Cuminá. Arquivos do Museu Nacional 32: 8-60.

SMITH, A. R., 1995a. Aspleniaceae. In: P. E. BERRY, B. K. HOLST \& K. YATSKIEVYCH (Eds.): Flora of the Venezuelan Guayana 2. Pteridophytes, Spermatophytes: Acanthaceae-Araceae: 12-22. Timber Press, Portland.

SMITH, A. R., 1995b. Blechnaceae. In: P. E. BERRY, B. K. HOLST \& K. YATSKIEVYCH (Eds.): Flora of the Venezuelan Guayana 2. Pteridophytes, Spermatophytes: Acanthaceae-Araceae: 23-29. Timber Press, Portland.
SMITH, A. R., 1992. Thelypteridaceae. In: R. M. TRYON \& R. G. STOLZE (Eds.): Pteridophyta of Peru. Part III. 16. Thelypteridaceae. Fieldiana Botany 29: 1-80.

SMITH, A. R., K. M. PRYER, E. SCHUETTPELZ, P. KORALL, H. SCHNEIDER \& P. G. WOLF, 2006. A classification for extant ferns. Taxon 55(3): 705-731.

SOTÃO, H. M. P., J. F. HENNEN, A. M. GUGLIOTTA, O. A. MELO \& E. L. CAMPOS, 1997. Os Fungos - Basidiomycota. In: P. L. B LISBOA (Ed.): Caxiuanã: 213-219. Museu Paraense Emílio Goeldi, Belém.

STOLZE, R. G., 1986. Polypodiaceae - Asplenioideae. In: G. HARLING \& B. SPARRE (Eds.): Flora of Ecuador 23: 1-83.

SYLVESTRE, L. S. \& C. G. V. RAMOS, 2005. Aspleniaceae. In: T. B. CAVALCANTI \& C. G. V. RAMOS (Eds.): Flora do Distrito Federal 4: 111-120.

SYLVESTRE, L. S. \& P. G. WINDISCH, 2002. New combinations in Antigramma C. Presl (Aspleniaceae) and a synopsis of the species. Bradea 8: 331-335.

TRYON, R. M. \& A. S. CONANT, 1975. The ferns of Brazilian Amazonica. Acta Amazônica 5(1): 23-34.

TRYON, R. M. \& R. G. STOLZE, 1994. Pteridophyta of Peru. Part. VI. 22. Marsileaceae-21. Isoetaceae. Fieldiana Botany, New series 33: 1-123.

TRYON, R. M. \& R. G. STOLZE, 1993. Pteridophyta of Peru. Part. I. 1. Ophioglossaceae - 12. Cyatheaceae. Fieldiana Botany, New series 20: 1-145.

TRYON, R. M. \& A. F. TRYON, 1982. Ferns and allied plants, with special reference to tropical America: 1-857. Springer-Verlag, New York.

TUOMISTO, H. \& A. T. GROOT, 1995. Identification of the juveniles of some ferns from Western Amazônia. American Fern Journal 85: 1-28.

WINDISCH, P. G., 1992. Pteridófitas da Região Norte-Ocidental do Estado de São Paulo - Guia para excursões: 1-110. 2 ed. Editora Universitária - UNESP, São José do Rio Preto.

WINDISCH, P. G. \& R. M. TRYON, 2001. The Serra Ricardo Franco (State of Mato Grosso, Brazil) as probable migration route and its present fern flora. Bradea 8(39): 267-276.

Recebido: 07/08/2007

Aprovado: 05/11/2008 
